\title{
Mechanistic Insight into Direct Arylations with Ruthenium(II) Carboxylate Catalysts
}

XXXX

Vol. xx, No. $x$

\section{Lutz Ackermann, ${ }^{*}$ Rubén Vicente, Harish K. Potukuchi, and Valentina Pirovano}

Institut fuer Organische und Biomolekulare Chemie, Georg-August-Universität,

Tammannstrasse 2, 37077 Göttingen, Germany

lutz.ackermann@chemie.uni-goettingen.de

Received September 13, 2010

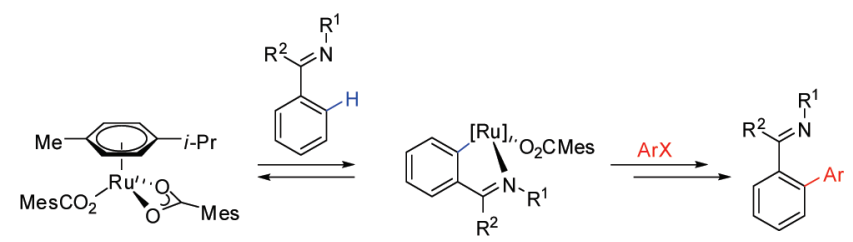

Mechanistic studies revealed ruthenium-catalyzed direct arylations to proceed through reversible $\mathrm{C}-\mathrm{H}$ bond activation and subsequent ratelimiting oxidative addition with aryl halides, which led to the development of widely applicable well-defined ruthenium(II) carboxylate catalysts.

Transition metal-catalyzed direct arylations of (hetero)arenes are increasingly viable alternatives to traditional crosscoupling reactions, which allow for an overall streamlining of arene syntheses. ${ }^{1,2}$ In recent years, ruthenium complexes have emerged as particularly attractive tools for $\mathrm{C}-\mathrm{H}$ bond functionalizations with inexpensive $\mathrm{e}^{3,4}$ easily accessible arylating reagents. ${ }^{5,6}$ Despite this significant progress, detailed experimental mechanistic studies on the working mode of

(1) Selected recent reviews: (a) Colby, D. A.; Bergman, R. G.; Ellman, J. A. Chem. Rev. 2010, 110, 624-655. (b) Ackermann, L.; Vicente, R.; Kapdi, A. Angew. Chem., Int. Ed 2009, 48, 9792-9826. (c) Thansandote, P.; Lautens, M. Chem.-Eur. J. 2009, 15, 5874-5883. (d) Kakiuchi, F.; Kochi, T. Synthesis 2008, 3013-3039. (e) Ackermann, L. Synlett 2007, 507526. (f) Satoh, T.; Miura, M. Chem. Lett. 2007, 36, 200-205.

(2) Ackermann, L. Modern Arylation Methods; Wiley-VCH: Weinheim, Germany, 2009.

(3) For selected recent examples of ruthenium-catalyzed direct arylations with aryl bromides, see: (a) Oi, S.; Sasamoto, H.; Funayama, R.; Inoue, Y. Chem. Lett. 2008, 37, 994-995. (b) Ackermann, L.; Althammer, A.; Born, R. Tetrahedron 2008, 64, 6115-6124. (c) Oi, S.; Funayama, R.; Hattori, T.; Inoue, Y. Tetrahedron 2008, 64, 6051-6059. (d) Ackermann, L.; Althammer, A.; Born, R. Synlett 2007, 2833-2836, and references cited therein.

(4) For select recent examples of ruthenium-catalyzed direct arylations with boron-based arylating reagents, see: (a) Kitazawa, K.; Kochi, T.; Sato, M.; Kakiuchi, F. Org. Lett. 2009, 11, 1951-1954. (b) Park, Y. J.; Jo, E.A.; Jun, C.-H. Chem. Commun. 2005, 1185-1187, and references cited therein.

(5) A review: Ackermann, L.; Vicente, R. Top. Curr. Chem. 2010, 292, 211-229. ruthenium catalysts in direct arylations with organic halides are unfortunately not available. Thus, several distinct reaction manifolds continue to be considered for these transformations. For instance, a rationale was put forward that involved an initial oxidative addition of aryl halides ${ }^{7}$ to ruthenium(II) complexes and a subsequent $\mathrm{C}-\mathrm{H}$ bond functionalization. ${ }^{8}$ On the contrary, computational DFT calculations were performed for direct arylations with in situ generated ruthenium(II) catalyst in NMP as solvent. ${ }^{9}$ On the basis of these studies and comparable isolated yields with differently

(6) Representative examples: ArOTs: (a) Ackermann, L.; Althammer, A.; Born, R. Angew. Chem., Int. Ed. 2006, 45, 2619-2622. ArCl: (b) Ackermann, L.; Born, R.; Álvarez-Bercedo, P. Angew. Chem., Int. Ed. 2007, 46, 6364-6367. (c) Pozgan, F.; Dixneuf, P. H. Adv. Synth. Catal. 2009, 351, 1737-1743. (d) Ackermann, L.; Born, R.; Vicente, R. ChemSusChem 2009, 2, 546-549. (e) In the presence of $\mathrm{H}_{2} \mathrm{O}$ : Ackermann, L. Org. Lett. 2005, 7, 3123-3125.

(7) Grounds, H.; Anderson, J. C.; Hayter, B.; Blake, A. J. Organometallics 2009, 28, 5289-5292.

(8) (a) Luo, N.; Yu, Z. Chem.-Eur. J. 2010, 16, 787-791. (b) Oi, S.; Sakai, K.; Inoue, Y. Org. Lett. 2005, 7, 4009-4011. (c) Oi, S.; Fukita, S.; Hirata, N.; Watanuki, N.; Miyano, S.; Inoue, Y. Org. Lett. 2001, 3, 25792581

(9) (a) Özdemir, I.; Demir, S.; Cetinkaya, B.; Gourlaouen, C.; Maseras, F.; Bruneau, C.; Dixneuf, P. H. J. Am. Chem. Soc. 2008, 130, 1156-1157. See also: (b) Davies, D. L.; Donald, S. M. A.; Macgregor, S. A. J. Am. Chem. Soc. 2005, 127, 13754-13755. (c) Boutadla, Y.; Davies, D. L.; Macgregor, S. A.; Poblador-Bahamonde, A. I. Dalton Trans. 2009, 58205831. 
substituted aryl bromides, ruthenium-catalyzed direct arylations were proposed to proceed through an irreversible carbonate-assisted $\mathrm{C}-\mathrm{H}$ bond metalation, along with a reversible oxidative addition of aryl bromides.

Recently, we disclosed the beneficial effect of carboxylic acids or carboxylates as additives in ruthenium-catalyzed $\mathrm{C}-\mathrm{H}$ bond functionalizations with organic halides. ${ }^{10,11}$ Given the novel working mode of these in situ generated catalytic systems, we became interested in identifying structurally well-defined ruthenium complexes, and in unravelling the mechanism of ruthenium-catalyzed $\mathrm{C}-\mathrm{H}$ bond functionalizations. As a result, we disclose herein our findings, which provide strong evidence for a mechanism involving a reversible $\mathrm{C}-\mathrm{H}$ bond metalation and an irreversible oxidative addition with aryl halides. Importantly, these studies also led to the isolation of structurally well-characterized ruthenium(II) carboxylate catalysts with ample scope.

At the outset, we performed stoichiometric experiments to elucidate the nature of the in situ generated catalyst. Hence, reaction of $\left[\mathrm{RuCl}_{2}(p \text {-cymene) }]_{2}\right.$ (1) with carboxylic acid $\mathbf{2}$ selectively delivered ruthenium(II) biscarboxylate complex 3 (Scheme 1). ${ }^{12}$

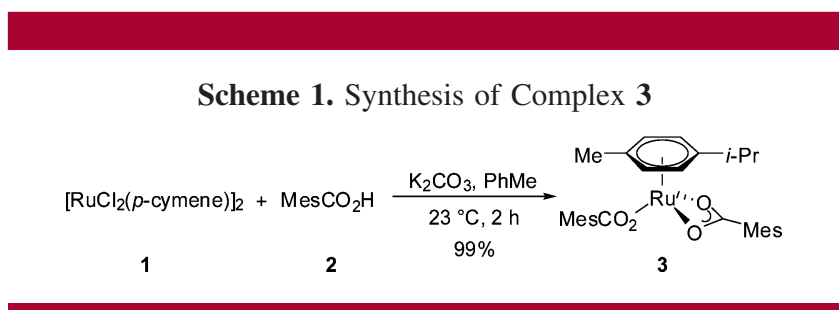

Importantly, well-defined ruthenium(II) carboxylate $\mathbf{3}$ was found to be catalytically competent even in toluene as solvent, ${ }^{13}$ and displayed a remarkable broad scope in the direct arylations of arenes 4 (Scheme 2). ${ }^{14}$ Thus, various arenes $\mathbf{4}$ were directly functionalized with differently substituted (hetero)aryl chlorides $\mathbf{5}$ in a highly regioselective fashion. Generally, transformations with electron-deficient aryl halides proceeded more efficiently (vide infra), and reactions with meta-substituted arenes 4 occurred with excellent site-selectivities, providing biphenyls $\mathbf{6 b a}-\mathbf{b e}$ through steric interactions as the sole products.

(10) Ackermann, L.; Vicente, R.; Althammer, A. Org. Lett. 2008, 10, 2299-2302.

(11) For examples of applications to direct arylations, see: (a) Ackermann, L.; Novák, P.; Vicente, R.; Pirovano, V.; Potukuchi, H. K. Synthesis 2010, 2245-2253. (b) Ackermann, L.; Vicente, R. Org. Lett. 2009 11, 4922-4925. (c) Ackermann, L.; Mulzer, M. Org. Lett. 2008, 10, 50435045. (d) Ackermann, L. Pure Appl. Chem. 2010, 82, 1403-1413. (e) For direct alkylations, see: Ackermann, L.; Novak, P.; Vicente, R.; Hofmann, N. Angew. Chem., Int. Ed. 2009, 48, 6045-6048. (f) Ackermann, L.; Novák, P. Org. Lett. 2009, 11, 4966-4969. (g) Ackermann, L. Chem. Commun. 2010, 46, 4866-4877.

(12) The crystal structure of complex $\mathbf{3}$ has been deposited at the Cambridge Crystallographic Data Centre (CCDC-757573).

(13) Mechanistic studies in NMP as solvent are hampered among others by its potential competitive coordination to ruthenium complexes, which in our hands results in catalytic reactions with lower robustness.

(14) Under otherwise identical reaction conditions, complex 1 provided product 6aa in the absence of $\mathrm{MesCO}_{2} \mathrm{H}$ in only unsatisfactory low yields of $8 \%$ (GC) or $47 \%$ when using $\mathrm{K}_{2} \mathrm{CO}_{3}$ or KOAc as base, respectively (see also Table S-1 in the Supporting Information).
Scheme 2. Direct Arylations with Well-Defined Complex 3
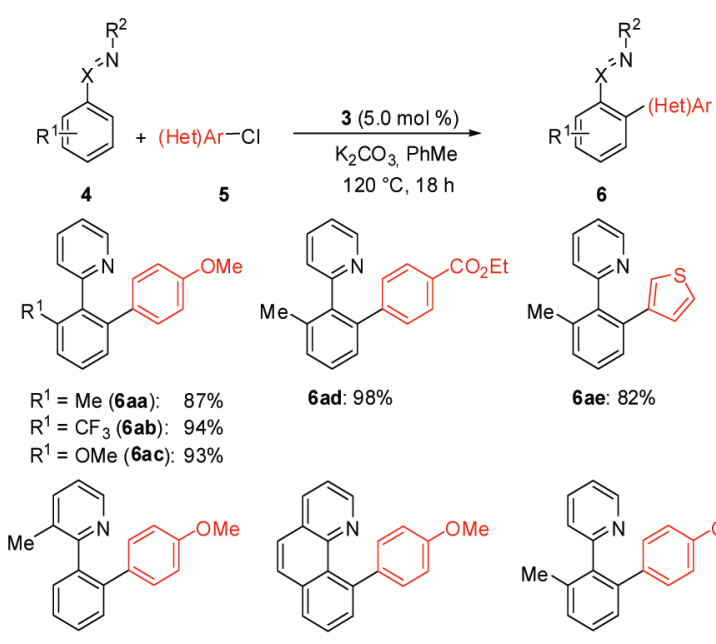

6ad: $98 \%$

6ae: $82 \%$

6af: $96 \%$
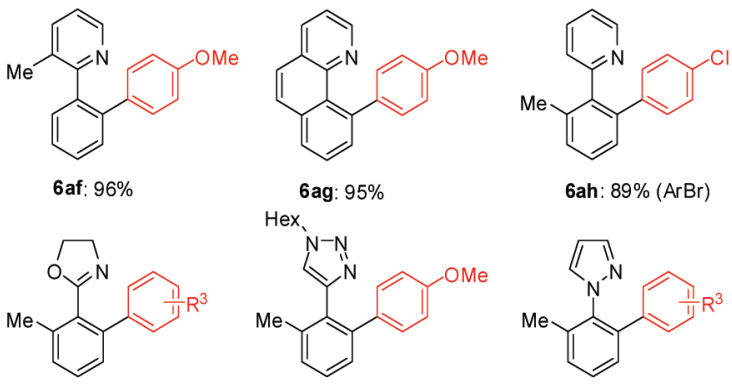

6ag: $95 \%$

Hex<smiles>C1CCN(N2CCCCC2)CC1</smiles><smiles>COc1ccc(-c2cccc(C)c2-c2cn[nH]n2)cc1</smiles>

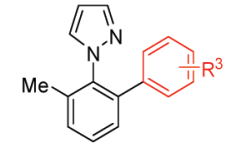

$\mathrm{R}^{3}=4-\mathrm{OMe}(6 \mathrm{ai}): \quad 75 \%$ $\mathrm{R}^{3}=2-\mathrm{OMe}(\mathbf{6 a j}): \quad 53 \%$ R $\mathrm{R}^{3}=4$ (C) $\quad 89 \%$ $\mathrm{R}^{3}=4-\mathrm{C}(\mathrm{O}) \mathrm{Me}(6 \mathrm{am}): 91 \%$
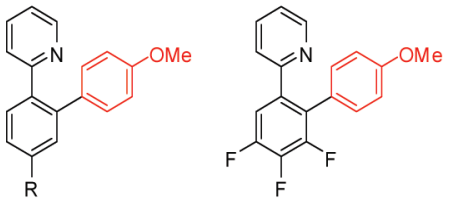

$\mathrm{R}^{3}=4-\mathrm{OMe}$ (6ao): $98 \%$ (with complex 1: 11\%) $\mathrm{R}^{3}=2-\mathrm{OMe}$ (6ap): $80 \%$ $\mathrm{R}^{3}=4-\mathrm{CF}_{3}(6 a q): 09 \%$ $\mathrm{R}^{3}=4-\mathrm{CO}_{2}$ Et (6ar): $97 \%$

$\mathrm{R}=\mathrm{H}$ (6as): $80 \%$ $\mathrm{R}=\mathrm{OMe}$ (6at): $80 \%$ 6av: $63 \%$

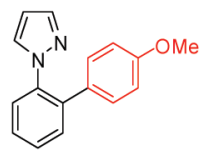

$\mathrm{R}=\mathrm{CF}_{3}(\mathbf{6 a u}): 80 \%$

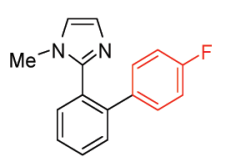

6ax: $86 \%$ (ArBr: 94\%) (Arl: 79\%)

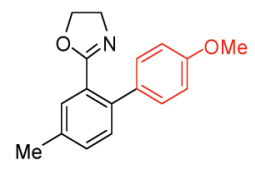

6ba: $50 \%$

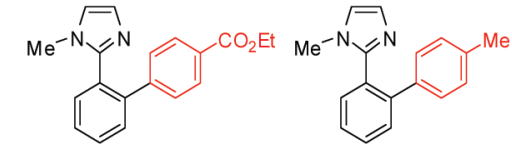

6ay: $95 \%$

6az: $91 \%$ (ArBr: $97 \%$ )

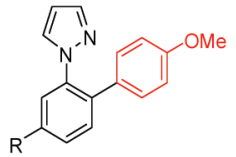

$\mathrm{R}=\mathrm{Me}(6 \mathrm{bb}): \quad 98 \%$ $\mathrm{R}=\mathrm{OMe}$ (6bc): $96 \%$

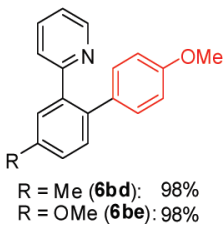

Notably, direct arylations of alkenes $\mathbf{4}$ enabled the diastereoselective formation of desired products $\mathbf{6}$ as well (Scheme 3).

Interestingly, intramolecular competition experiments with $m$-fluoro-substituted arenes $\mathbf{4 b}$ and $\mathbf{4 c}$ delivered predominantly biphenyls $\mathbf{6 b o}$ and $\mathbf{6 b q}$, respectively (Scheme 4). ${ }^{15}$

Given the remarkable reactivity profile of complex $\mathbf{3}$, we subsequently probed its mode of action through

(15) (a) Shen, K.; Fu, Y.; Li, J.-N.; Liu, L.; Guo, Q.-X. Tetrahedron 2007, 63, 1568-1576. (b) Clot, E.; Mégret, C.; Eisenstein, O.; Perutz, R. N. J. Am. Chem. Soc. 2009, 131, 7817-7827. 
Scheme 3. Direct Arylations of Alkenes 4

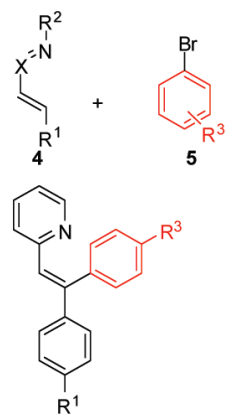

$R^{1}=H, R^{3}=O M e(6 b f): 90 \%$ $R^{1}=R^{3}=$ OMe $(6 \mathrm{bg}): 89 \%$

$\mathrm{R}^{3}=\mathrm{OMe}(\mathbf{6 b i}): 82 \%$
$\mathrm{R}^{3}=\mathrm{CF}_{3}(\mathbf{6 b j}): 58 \%$

$R^{3}=C(0) M e(6 b k): 62 \%$

$\mathrm{R}^{1}=\mathrm{H}, \mathrm{R}^{3}=\mathrm{C}(\mathrm{O}) \mathrm{Me}(6 \mathrm{bh}): 76 \%$
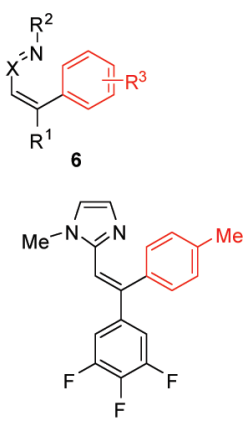

6bl: $68 \%$

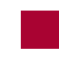

Scheme 4. Intramolecular Competition Experiments with $m$-Fluoro-Substituted Arenes

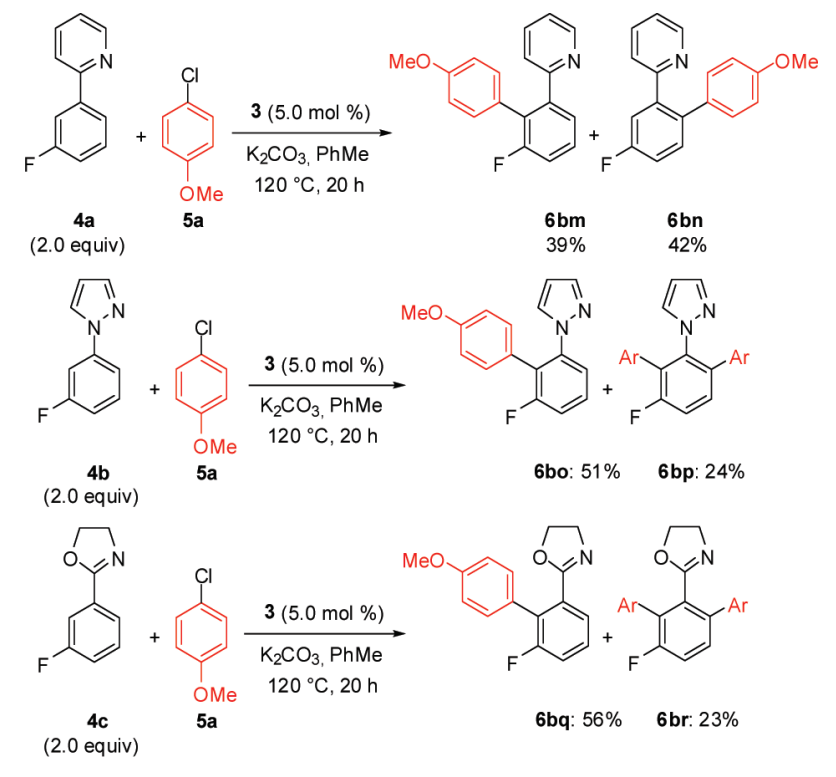

stoichiometric experiments (Scheme 5). Hence, ruthenium(II) carboxylate 3 turned out to be inert in the presence of aryl chloride $\mathbf{5 a}$, even at elevated reaction temperatures. Contrarily, cyclometalation of arene $\mathbf{4 b}$ occurred readily, thereby yielding catalytically competent cyclometalated complex 7. ${ }^{16}$

Importantly, experiments with isotopically labeled starting materials clearly revealed a D/H-exchange ${ }^{17}$ reaction (Scheme 6). Contrary to previous proposals, these results suggest the $\mathrm{C}-\mathrm{H}$ bond metalation step to be reversible in nature.

Moreover, competition experiments with an excess of differently substituted electrophiles showed that electrondeficient aryl halides reacted preferentially (Scheme 7). This

(16) Generally, the following order in reactivity is observed in rutheniumcatalyzed direct arylations: $\mathrm{ArBr}>\mathrm{ArCl}>\mathrm{ArOTs}$. For the synthesis of a cyclometalated complex, see: Fernandez, S.; Pfeffer, M.; Ritleng, V.; Sirlin, C. Organometallics 1999, 18, 2390-2394. See also ref 5.

Scheme 5. Synthesis of and Catalysis with Cyclometalated Complex 7
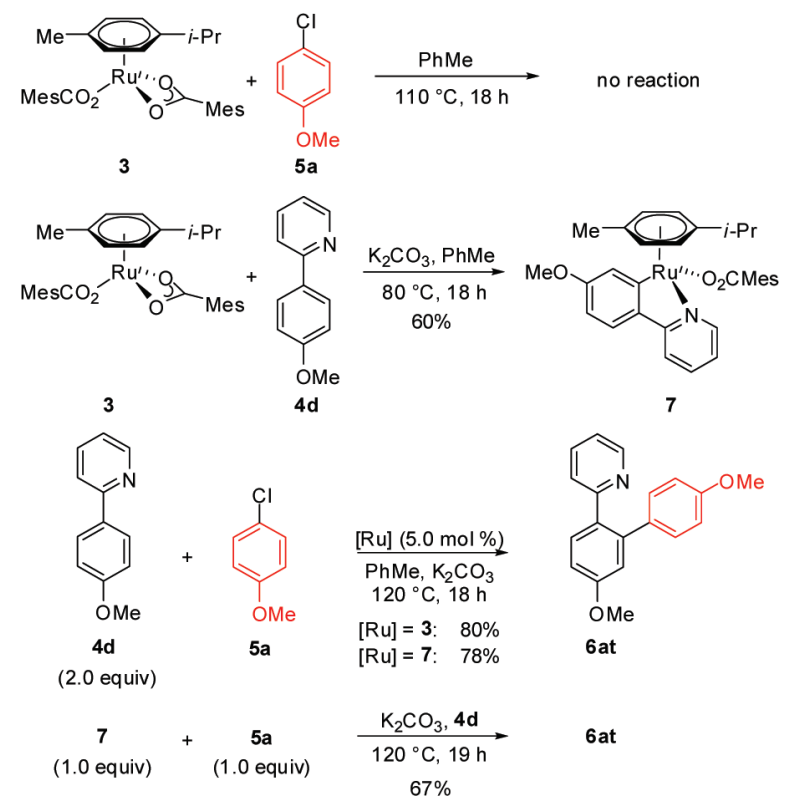

Scheme 6. Catalytic Direct Arylation with Isotopically Labeled Starting Materials
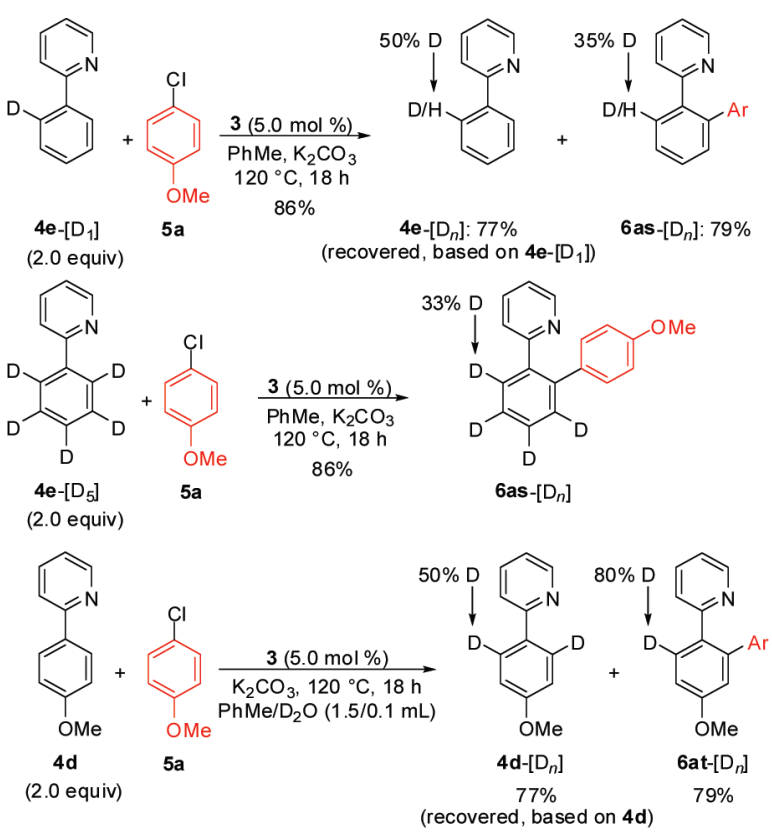

chemoselectivity was independent of the nature of the leaving group or solvent, and optimal isolated yields were obtained in toluene.

On the basis of our experimental studies we propose complex 3 to undergo an initial reversible cyclometalation through a carboxylate-assisted deprotonation (Scheme 8). ${ }^{18}$ Thereafter, complex 7 reacts in the rate-limiting step with aryl halide $\mathbf{5}$ to yield intermediate $9 .{ }^{19}$ Finally, reductive 
Scheme 7. Intermolecular Competition Experiments

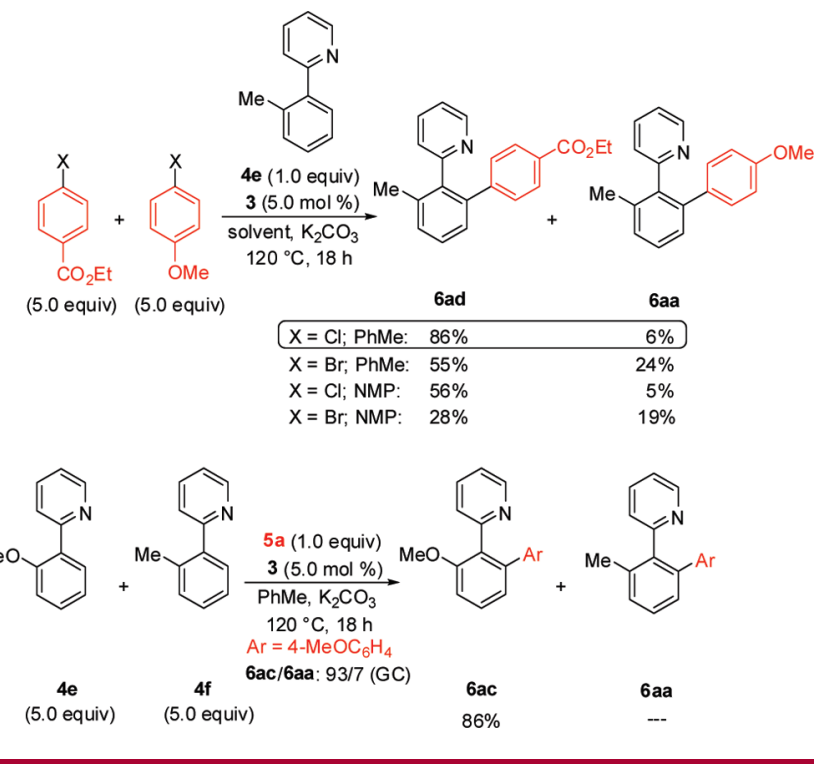

elimination regioselectively gives rise to functionalized arenes $\mathbf{6}$, and thereby regenerates catalyst $\mathbf{3}$.

In summary, we have provided strong experimental evidence for ruthenium-catalyzed direct arylations to proceed

(17) For previous studies on the reversibility of ruthenium-catalyzed $\mathrm{C}-\mathrm{H}$ bond cleavage/ $\mathrm{C}-\mathrm{C}$ bond formation reactions, see: (a) Kozhushkov, S. I.; Yufit, D. S.; Ackermann, L. Org. Lett. 2008, 10, 3409-3412, and references cited therein. (b) During the preparation of this manuscript a study on ruthenium-catalyzed $\mathrm{C}-\mathrm{H}$ bond functionalizations in NMP as solvent was reported: Prades, A.; Poyatos, M.; Peris, E. Adv. Synth. Catal. 2010, 352, 1155-1162.

(18) Addition of 1 equiv of 2,6-di-tert-butyl-p-cresol or catalytic amounts of galvinoxyl did not affect the outcome of representative rutheniumcatalyzed direct arylations with aryl chlorides 5. However, lower yields were obtained when employing 1 equiv of galvinoxyl or of TEMPO. For reactions of radical traps with transition metal hydrides, see for example: Albéniz, A. C.; Espinet, P.; López-Fernández, R.; Den, A. J. Am. Chem. Soc. 2002, 124, 11278-11279.

(19) Intermolecular competition experiments between differently substituted arenes $\mathbf{4}$ indicate the oxidative addition, rather than the reductive elimination to be rate determining (see Scheme 7, and Scheme S-1 in the Supporting Information).
Scheme 8. Proposed Mechanism of Ruthenium-Catalyzed Direct Arylations

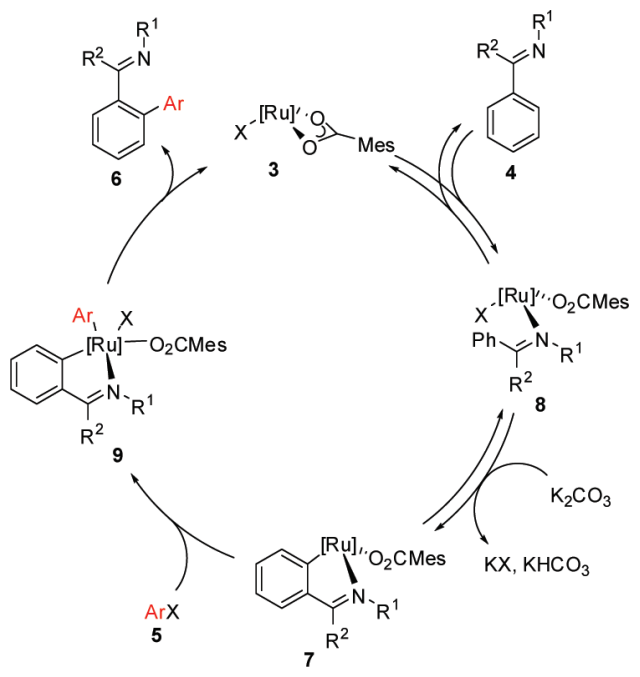

through a reversible $\mathrm{C}-\mathrm{H}$ bond metalation, along with a subsequent rate-determining activation of the aryl halide. In addition, we prepared novel well-defined ruthenium(II) carboxylate complexes with ample scope and high activity in $\mathrm{C}-\mathrm{H}$ bond arylations.

Acknowledgment. Support by the DFG, as well as the DAAD and the Alexander-von-Humboldt foundation (fellowships to H.K.P. and R.V., respectively), is gratefully acknowledged. Further, we thank Dr. Carola Schulzke (Trinity College Dublin, Ireland) for an X-ray crystal structure analysis of complex $\mathbf{3}$.

Supporting Information Available: Experimental procedures, characterization data, and ${ }^{1} \mathrm{H}$ and ${ }^{13} \mathrm{C}$ NMR spectra for new compounds. This material is available free of charge via the Internet at http://pubs.acs.org.

OL102187E 